\title{
EFICIÊNCIA REPRODUTIVA DE REBANHOS LEITEIROS DA RAÇA JERSEY ORIUNDOS DA AGRICULTURA FAMILIAR DO MUNICÍPIO DE REALEZA-PR
}

\author{
Yuri da Fontoura Porto \\ Mônica Zuchelli Jaguszeski ${ }^{1}$ \\ Adalgiza Pinto-Neto ${ }^{2}$ \\ Marcelo Falci Mota ${ }^{2}$ \\ Fernando Skonieski² \\ Luiz Sérgio Merlini ${ }^{3}$ \\ Rodolfo Berber ${ }^{4}$
}

PORTO, Y. da F.; JAGUSZESKI, M. Z.; PINTO-NETO, A.; MOTA, M. F.; SKONIESKI, F.; MERLINI, L. S.; BERBER, R. Eficiência reprodutiva de rebanhos leiteiros da raça Jersey oriundos da agricultura familiar do município de Realeza-PR. Arq. Ciênc. Vet. Zool. UNIPAR, Umuarama, v. 20, n. 1, p. 15-18, jan./mar. 2017.

\begin{abstract}
RESUMO: A produção de leite na Região do Sudoeste do Paraná teve desenvolvimento notável nos últimos anos, tornando esta região uma importante bacia leiteira na produção estadual e nacional, sendo que a maior parte desta produção é proveniente de rebanhos que fazem parte da produção familiar. O presente trabalho tem como objetivo avaliar a eficiência reprodutiva de bovinos da Raça Jersey oriundos de rebanhos leiteiros de produção familiar, do Município de Realeza-PR. Para tanto, identificou-se no Município de Realeza-PR, um único rebanho bovino da Raça Jersey pura, desconsiderando aqueles com animais oriundos de cruzamentos com essa raça. Dessa forma, analisou-se a eficiência reprodutiva (ER) desse rebanho, contendo 33 vacas Jersey Puras de Origem, em lactação. A idade e o peso das fêmeas estudadas foi de 4,39 $\pm 2,04$ anos e $402,58 \pm 49,56$ quilos, respectivamente. Cada fêmea pariu 2,52 $\pm 1,8$ vezes, sendo a idade ao primeiro parto de 2,19 $\pm 0,57$ anos. Os animais apresentaram intervalo de partos de 377 dias, número médio de serviços concepção de 1,77 e período médio de serviço de 105 dias. Considerando todo período reprodutivo útil das fêmeas estudadas, que variou de uma a dez concepções seguidas de gestação, $61 \%$ delas ficaram gestantes na primeira IA. A taxa de natalidade do rebanho durante o período de estudo foi de $90,9 \%$, sendo considerada adequada, e a de aborto/natimortos de $10 \%$. Observou-se viabilidade produtiva e reprodutiva para a produção de leite a partir do rebanho estudado.
\end{abstract}

PALAVRAS-CHAVE: Bovino. Eficiência produtiva. Eficiência reprodutiva. Produção de leite.

\section{REPRODUCTIVE EFFICIENCY OF JERSEY DAIRY CATTLE HERDS FROM FAMILY FARMING IN THE CITY OF REALEZ, PARANÁ}

\begin{abstract}
Milk production in the southwestern region of the state of Paraná has increased in recent years, transforming the region in an important dairy farming area in both state and national production. Most of this production is originated from herds in family farming. This study aimed to evaluate the reproductive efficiency of Jersey cattle herds from family farms located in the city of Realeza, in the state of Paraná. IN order to do so, the researchers identified pure Jersey herds in the city, disregarding any other with animals originated from mixed-breeding with this race. In total, 33 lactating animals were evaluated. The age and weight of the cows were $4.39 \pm 2.04$ years old and $402.58 \pm 49.56 \mathrm{~kg}$, respectively. On average, each cow had given birth to $2.52 \pm 1.8$ calves, with the age first calving of $2.19 \pm 0.57$ years. The animals had 377 days of calving interval, average number of conception services of 1.77, and service mean of 105 days. Considering the entire useful reproductive period of the cows, which ranged from one to ten conceptions followed by pregnancy, $61 \%$ of them became pregnant at the first AI. The birth rate of the herd during the experiment was $90.9 \%$, which is considered adequate, and presenting an abortion/stillbirth rate of $10 \%$. Productive and reproductive viability could be observed for milk production from the studied herd. KEYWORDS: Bovine. Milk production. Productive efficiency. Reproductive efficiency.
\end{abstract}

\section{EFICIENCIA REPRODUCTIVA DE GANADO LECHERO DE LA RAZA JERSEY PROCEDENTES DE AGRICULTURA FAMILIAR EN EL MUNICIPIO DE REALEZA-PR}

\footnotetext{
RESUMEN: La producción de leche en la región del sudoeste de Paraná tuvo un notable desarrollo en los últimos años, haciendo de esta región una importante región lechera a nivel estatal y nacional, siendo que la mayor parte de esta producción proviene de rebaños de producción familiar. Este estudio tuvo como objetivo evaluar la eficiencia reproductiva de bovinos de la raza Jersey procedentes de rebaños lecheros de producción familiar, del municipio de Realeza-PR. Por lo tanto, se identificó en el Municipio de Realeza-PR un solo rebaño de la raza Jersey, excluyéndose aquellos rebaños con animales derivados

DOI: https://doi.org/10.25110/arqvet.v20i1.2017.6314

${ }^{1}$ Acadêmicos do Curso de Medicina Veterinária - Campus Realeza-UFFS.

2Docentes do Curso de Medicina Veterinária. Campus Realeza-UFFS. Correspondência aos autores: adalgiza.neto@uffs.edu.br; adalgiza.uffs@gmail.com

${ }^{3}$ Docente. Programa de Pós-Graduação em Saúde Animal. Universidade Paranaense.Campus Umuarama.

${ }^{4}$ Docente do Curso de Medicina Veterinária. Campus Sinop. Universidade Federal do Mato Grosso.
} 
de cruces con esta raza. Así, se analizó la eficiencia reproductiva (ER) de ese rebaño, con 33 vacas Jersey puras de origen, en periodo de lactancia. La edad y el peso de las hembras estudiadas fueron de 4,39 \pm 2,04 años y 402,58 \pm 49,56 kilogramos, respectivamente. Cada hembra dio la luz a 2,52 $\pm 1,8$ veces, siendo la edad al primer parto de 2,19 $\pm 0,57$ años. Los animales presentaron intervalo entre partos de 377 días, promedio del número de servicios de concepción de 1,77 y período promedio de servicio de 105 días. Teniendo en cuenta todo el período reproductivo útil de las hembras estudiadas, que oscilaron de uno a diez concepciones seguidas de embarazo, $61 \%$ de las mismas se quedaron embarazadas en la primera inseminación artificial. La tasa de natalidad del rebaño durante el período investigado fue de 90,9\% y es considerada adecuada, mientras que la tasa de aborto/mortinatos de 10\%. Se observó la viabilidad de reproducción y la producción de leche del rebaño estudiado.

PALABRAS CLAVE: Bovino. Eficiencia productiva. Eficiencia reproductiva. Producción de leche.

\section{Introdução}

A pecuária leiteira na Região do Sudoeste do Paraná é uma das principais atividades desenvolvidas, destacando-se como uma das principais bacias leiteiras do país. Ao se classificar os produtores segundo a produção diária, verifica-se que há uma grande concentração de propriedades que produzem uma faixa de 50 litros/dia, correspondendo um total de $14,7 \%$ da produção geral do Estado (WIRBISK et al., 2009).

O Sudoeste do Paraná, especificamente o Município de Realeza-PR, conta com 9.127 vacas ordenhadas (IBGE, 2015). No Estado do Paraná a maioria dos produtores de leite possuem animais mestiços, no entanto, na Região Sudoeste do Estado, além de gado Holandês, animais da raça Jersey possuem uma participação expressiva, devido possivelmente à adaptabilidade desta raça às condições de relevo e clima dessa região. Nesse contexto, vacas da raça Jersey se destacam, sendo capazes de atender as necessidades e/ou particularidades do produtor familiar (WIRBISK et al., 2009).

A composição química do leite de vacas pode variar de acordo com a raça, sendo que as diferenças são especialmente em gordura e proteína, sendo esses componentes as bases de pagamento diferenciado para os produtores de leite (GONZÁLEZ; CAMPOS, 2003). A porcentagem de gordura do leite da raça Jersey é maior que da raça Holandesa, sendo que a média da raça Jersey é de 5 a 5,5\% (GONZÁLEZ; CAMPOS, 2003), enquanto a da raça Holandesa é 3,45 a 3,75\% (DURÃES et al., 2001).

Neste contexto, bovinos da Raça Jersey, poderiam ser uma opção para a produtividade dos rebanhos leiteiros, por serem animais dóceis, rústicos, de menor tamanho, de alta precocidade reprodutiva e longevidade, estando no ranking de raças leiteiras mais produtivas (SOARES, 2012). Além disso, possuem alta eficiência na produção de leite por hectare, alta prolificidade, adaptabilidade, qualidade do leite destacada, valor agregado no reprodutor, e qualidade na transmissão de características desejáveis a progênie (HENRIQUE, 2009).

Associam-se às características apresentadas, a produção econômica de leite, onde fêmeas bovinas Jersey apresentam alta eficiência na conversão alimentar, destacando-se por ser a raça que mais produz leite nas pequenas e médias propriedades (SOARES, 2012).

Em um sistema de produção leiteira em que a reprodução é ineficiente, ocorre aumento no descarte involuntário, diminuição da longevidade e do número de animais para reposição, menor progresso genético, maior gasto com inseminação e com medicamentos. Desse modo, há redução na produção de leite, pelo aumento do intervalo de lactações e também prolongamento do período seco da vaca, além do aumento da proporção de vacas secas no rebanho (BERGA-
MASCHI; MACHADO; BARBOSA, 2010).

No Brasil, a produção leiteira poderia ser elevada em até $50 \%$ com a redução do intervalo de partos (IP) do rebanho nacional para próximo de 12 meses, o que representaria um acréscimo anual de cerca de 11 bilhões de litros de leite além de um aumento expressivo do número de bezerros nascidos (FERREIRA; TEIXEIRA, 2000).

Diante disso, a avaliação da eficiência reprodutiva (ER) é um ponto crítico para a lucratividade do rebanho de leite, e deve ser feita sempre associada ao manejo zootécnico, considerando o gerenciamento das informações relativas ao rebanho. Nesse sentido, a avaliação de parâmetros que garantam a ER, incluindo idade do primeiro parto, período de serviço, intervalo de parto e produção de leite por animal indicarão a situação do manejo reprodutivo da propriedade, permitindo que sejam adotadas técnicas de manejo capazes de melhor sua produtividade (ZOCCAL et al., 2004).

Observa-se então que a ER e a produção de leite são fatores determinantes no retorno econômico da pecuária de leite. Problemas reprodutivos podem tornar a atividade menos rentável pela diminuição do número de animais produzidos e pela elevação dos custos com coberturas ou inseminações artificiais (AZEVEDO; AZEVEDO; ALVES, 2001).

Desse modo, considerando a contribuição com a melhoria da atividade leiteira do município, objetiva-se com este estudo avaliar a eficiência reprodutiva de um rebanho bovino leiteiros da Raça Jersey, de Produção Familiar, do Município de Realeza - PR.

\section{Material e Métodos}

Para realização deste estudo identificou-se rebanhos bovinos da raça Jersey, puros de origem, inseridos em sistema de produção familiar, no Município de Realeza - PR. Coletou-se dados zootécnicos de cada fêmea púbere dos rebanhos a serem estudados, que foram anotados, tabulados e organizados em planilhas eletrônicas.

Os dados de interesse foram baseados naqueles utilizados para o cálculo de índices de ER, segundo a descrição de Ferreira e Miranda (2007), sendo:

- Intervalo de parto (IP): tempo transcorrido entre dois partos consecutivos de uma mesma vaca, e corresponde ao período de serviço (PS) mais o período de gestação;

- Período de serviço (PS): tempo que decorre do parto até nova concepção, considerando apenas fêmeas que já pariram pelo menos uma vez;

- Taxa de Natalidade: número de bezerros nascidos vivos durante todo o ano, dividido pelo número médio mensal das vacas, multiplicado por 100 ; 
- Porcentagem de gestação ao primeiro serviço: quantidade de vacas gestantes após a primeira IA ou monta natural, divido pelo total de vacas inseminadas/cobertas, multiplicado por 100 ;

- Taxa de gestação: número de vacas gestantes dividido pelo número total de vacas inseminadas ou cobertas por MN, multiplicado por 100 ;

- Idade ao primeiro parto (IPP): idade que ocorre o primeiro parto, e

- Taxa de natimortos/abortos: é a quantidade de fetos abortados ou natimortos por mês/ano, multiplicado por 100 .

Os dados coletados foram tabulados e analisados, utilizando-se o Programa Excel, sendo apresentados sob a forma descritiva.

\section{Resultados e Discussão}

Santos-Júnior (2016) identificou 255 rebanhos bovinos leiteiros de produção familiar, no Município de Realeza, dos quais $53,73 \%(137 / 255)$ eram compostos por raças mestiças, 16,47\% (42/255) por Raça Holandesa, 14,9\% $(38 / 255)$ por raças Jersey x Holandês, $12,94 \%$ (33/255) por Raça Jersey e 1,96\% (5/255) por mestiços Gir x Holandês. No entanto, dos rebanhos identificados como Raça Jersey, somente um deles $(3,03 \%$ - 1/33) possui animais da Raça Jersey puros. Talvez essa diferença nos dados seja explicada pelo desconhecimento do proprietário do padrão da raça, ao responder o questionário aferido pelo autor.

Do rebanho estudado, 33 vacas, da raça Jersey, puras de origem em lactação foram utilizadas, sendo, a idade e o peso das fêmeas estudadas de 4,39 $\pm 2,04$ anos e 402,58 $\pm 49,56$ quilos, respectivamente. O número de fêmeas em lactação no rebanho estudado foi superior ao número médio delas em rebanhos leiteiros de produção familiar (SANTOS-JÚNIOR, 2016).

Cada fêmea pariu 2,52 $\pm 1,8$ vezes, sendo a idade ao primeiro parto (IPP) de 2,19 $\pm 0,57$ anos, sendo semelhante ao relatado por Vercesi Filho et al. (2007), onde a IPP desejável estaria em aproximadamente dois anos. A IPP média relatada nesse estudo é mais precoce em relação ao estudo de Grossi e Freitas (2002), ao estudarem índices reprodutivos de bovinos leiteiros no Sudeste no Brasil, utilizando um rebanho de vacas mestiças, holandês-zebu, relatando IPP médio de 32 meses. Inegavelmente muito desses índices estão relacionados ao tipo de manejo nutricional, sanitário e reprodutivo que é adotado na propriedade.

Pereira et al. (2013) relataram que a performance reprodutiva é um ponto crítico na viabilidade da atividade na produção, sendo ela familiar, ou não. $\mathrm{O}$ intervalo de partos pode ser considerado um índice importante para a mensuração da eficiência reprodutiva de um rebanho, sendo que o período de até 380 dias é considerado ideal para o rebanho, resultando em uma cria por ano (FERREIRA; MIRANDA, 2007; PEREIRA et al., 2013). Neste estudo, os animais apresentaram intervalo de partos de 377 dias, correspondendo a índice muito satisfatório, de acordo com o citado na literatura como o ideal para rebanhos leiteiros (GROSSI; FREITAS, 2002).

O número de serviços por concepção e o aumento no intervalo de parto são índices que indicam que está se perdendo a eficiência reprodutiva. Nesse estudo, o número de IA por concepção foi de 1,77, estando de acordo com aqueles citados por Ferreira e Miranda (2007) de superior a dois, e por Bergamasch, Machado e Barbosa (2010) de 1,7 a 2,2.

O período médio de serviço encontrado nesse estudo foi de 105 dias, estando dentro dos parâmetros desejáveis, para que seja possível alcançar o IP de 12 meses (PEREIRA et al.,2013). Destaca-se a importância da prevenção de problemas reprodutivos como a ocorrência de retenção de placenta, o manejo nutricional e as condições de escore corporal que podem afetar negativamente esse índice.

Considerando o período reprodutivo útil das fêmeas estudadas, que variou de uma a dez concepções seguidas de gestação, a porcentagem de gestação ao primeiro serviço foi de $61 \%$, estando dentro dos parâmetros desejáveis de acordo com Ferreira e Miranda (2007) e Bergamaschi, Machado e Barbosa (2010), de inferior a $50 \%$ e de $35-40 \%$, respectivamente.

A taxa de natalidade do rebanho durante o período de estudo foi de $90,9 \%$, e a de aborto/natimortos de $10 \%$, sendo superior ao citado como desejável ( $5 \%$ de taxa de natimortos/abortos por ano) (GROSSI; FREITAS, 2002; FERREIRA; MIRANDA 2007; BERGAMASCHI; MACHADO; BARBOSA, 2010).

Mesmo sabendo que a produção leiteira do $\mathrm{Mu}-$ nicípio de Realeza seja proveniente de pequenos rebanhos leiteiros, sendo $96 \%$ inseridos em sistema de produção familiar (SANTOS-JÚNIOR, 2016), observou-se com esse estudo, que somente um desses rebanhos utilizam bovinos da raça Jersey puros de origem. Esse autor relatou que dos 255 rebanhos estudados no Município de Realeza, 53,73\% (137/255) são compostos por animais de raças mestiças, 16,47\% (42/255) de Raça Holandês, 14,90\% (38/255) rebanhos com Raças Jersey e Holandês, 12,94\% (33/255) de Jersey e 1,96\% (5/255) de mestiços Gir-Holandês. Possivelmente a diferença relatada deve-se a não confirmação racial dos animais desses rebanhos.

A utilização de bovinos da Raça Jersey, poderia ser uma opção para a produtividade dos rebanhos leiteiros em produção familiar, por serem animais dóceis, rústicos, de menor tamanho, de alta precocidade reprodutiva e longevidade, estando no ranking de raças leiteiras mais produtivas (HENRIQUE, 2009; SOARES, 2012).

\section{Conclusão}

Observou-se viabilidade produtiva e reprodutiva para a produção de leite a partir no rebanho estudado, bem como a alta gordura do leite que a raça dispõe (chegando até $5,5 \%$ ), que poderia tornar o leite maior competitividade no mercado. No entanto, a extrapolação desses resultados para outros rebanhos e/ou para bovinos da Raça Jersey, precisa ser cautelosa, uma vez que estes dados podem não expressar a realidade de todos os animais desta raça, e sim em uma população específica.

\section{Referências}

AZEVEDO, D. M. M. R.; AZEVEDO, A. R.; ALVES, A. A. Eficiência reprodutiva em bovinos de leite. Revista de 
Ciência e Produção Animal, v. 3, n. 2, p. 48-61, 2001.

BERGAMASCHI, M. A. C. M.; MACHADO, R.; BARBOSA, R. T. Eficiência reprodutiva em vacas leiteiras. Embrapa - Circular Técnica 64. São Carlos - SP. Nov. 2010.

DURÃES, M. C. et al. Tendência Genética para a Produção de Leite e de Gordura em Rebanhos da Raça Holandesa no Estado de Minas Gerais. Revista Brasileira de Zootecnia, v. 30, n. 1 , p. $66-70,2001$.

FERREIRA, A. M.; TEIXEIRA, N. M. Estimativas de mudanças na produção de leite com a variação do intervalo de partos em rebanhos bovinos. Revista Brasileira de Reprodução Animal, v. 24, n. 4, p. 177-181, 2000.

FERREIRA, A. M.; MIRANDA, J. E. C. Medidas de eficiência da atividade leiteira: índices zootécnicos para rebanhos leiteiros. Embrapa - Circular Técnica 54. Juiz de Fora - MG. 2007.

GONZÁLEZ, F. H. D.; CAMPOS, R. Indicadores metabólico-nutricionais do leite. IN: SIMPÓSIO DE PATOLOGIA CLÍNICA VETERINÁRIA DA REGIÃO DO SUL DO BRASIL. 2003, Porto Alegre. Anais... Porto Alegre: Gráfica da Universidade Federal do Rio Grande do Sul.

GROSSI, S. F.; FREITAS, M. A. R. Eficiência reprodutiva e produtiva em rebanhos leiteiros comerciais monitorados por sistema informatizado. Revista Brasileira de Zootecnia, v. 31, n. 3, p. 1362-1366, 2002.

HENRIQUE, M. Holandês vs Jersey: um comparativo entre raças. Disponível em: $<\mathrm{http}: / /$ marcosveterinario. blogspot.com/2009/04/holandes-vs-Jersey-um-comparativoentre.html> Acesso em: 03 jun. 2013.

\section{INSTITUTO BRASILEIRO DE GEOGRAFIA E}

ESTATISTICA. Censo Agropecuário. 2015. Disponível em: http://www.ibge.gov.br/cidadesat. Acesso em: $21 \mathrm{dez}$. 2016.

PEREIRA, P. A. C. et al. Comparação dos índices de eficiência reprodutiva por diferentes métodos em rebanhos bovinos leiteiros. Arquivo Brasileiro de Medicina

Veterinária e Zootecnia, v. 65, n. 5, p. 1383-1388, 2013.

SANTOS-JÚNIOR, N. L. et al. Productive and reproductive profile of dairy farms from Realeza, Parana, Brazil.

Livestock Research for Rural Development, v. 28, n. 9, p.1-6, 2016.

SOARES, R. F. O Gado Jersey. 2012. Disponível em:

$<$ http://assisbrasil.org/Jersey.htm> Acesso em: 01 jun. 2013.

VERCESI FILHO, A. E. et al. Parâmetros genéticos entre características de leite, de peso e a idade ao primeiro parto em gado mestiço leiteiro (Bos taurus $x$ Bos indicus).

Arquivo Brasileiro de Medicina Veterinária e Zootecnia, v. 59, n. 4, p. 983-990, 2007.

WIRBISKI, S. et al. Caracterização socioeconômica da atividade leiteira do Paraná. In: CONGRESSO

SOCIEDADE BRASILEIRA DE ECONOMIA, ADMINISTRAÇÃO E SOCIOLOGIA RURAL, 47., 2009, Anais... Porto Alegre: SOBER, 2009

ZOCCAL, R. et al. Produção de leite na agricultura familiar. CONGRESSO SOCIEDADE BRASILEIRA DE ECONOMIA RURAL, 42., 2004. Anais... Cuiabá: SOBER, 2004.

Recebido em: 20.09.2016 Aceito em: 06.02.2017 